\title{
Evaluation of Two-phase suction, Liquid Injection and Two-phase Injection for Decreasing the Discharge Temperature of the R32 Scroll Compressor
}

Minghong Yang ${ }^{a}$, Baolong Wang ${ }^{\mathrm{a}, *}$, Xianting Li $^{\mathrm{a}}$, Wenxing Shi ${ }^{\mathrm{a}}$, Leping Zhang ${ }^{\mathrm{b}}$

${ }^{a}$ Department of Building Science, School of Architecture, Tsinghua University, Beijing, 100084, China

${ }^{b}$ Danfoss (Tianjin) Ltd, Commercial Scroll Compressor, Tianjin, China

* Corresponding author: Baolong Wang

Department of Building Science, School of ArchitectureTsinghua University Beijing, 100084, China

Tel: +86-10-62786571

Fax: +86-10-62773461

E-mail:wangbl @tsinghua.edu.cn 


\begin{abstract}
R32 has been considered as an important alternative in the phase-out of hydrochlorofluorocarbons (HCFCs) due to its advantages such as relatively low global warming potential compared to R410A, favorable thermal properties. However, the increased discharge temperature of the R32 compressor, compared with R410A, is the main barrier affecting the wide and quick adoption. In this work, three promising methods to decrease the discharge temperature of R32 scroll compressor, namely, two-phase suction, liquid injection and two-phase injection, have been investigated. By considering the variations of motor efficiency and leakage rate, an improved distributed parameter model of the scroll compressor is rebuilt based on a previously developed one (Wang et al., 2008). By that model, the effectiveness of these three methods in decreasing discharge temperature and their influence on thermodynamic performance are researched. It is concluded that all the three methods show excellent potential in decreasing the discharge temperature of R32 scroll compressor. Besides, two-phase injection outperforms the other two methods in cooling capacity and COP by $11.8 \%$ and $4.8 \%$, respectively.
\end{abstract}

\title{
Keywords
}

R32; discharge temperature; two-phase suction; two-phase injection; liquid injection 


\section{Nomenclature}

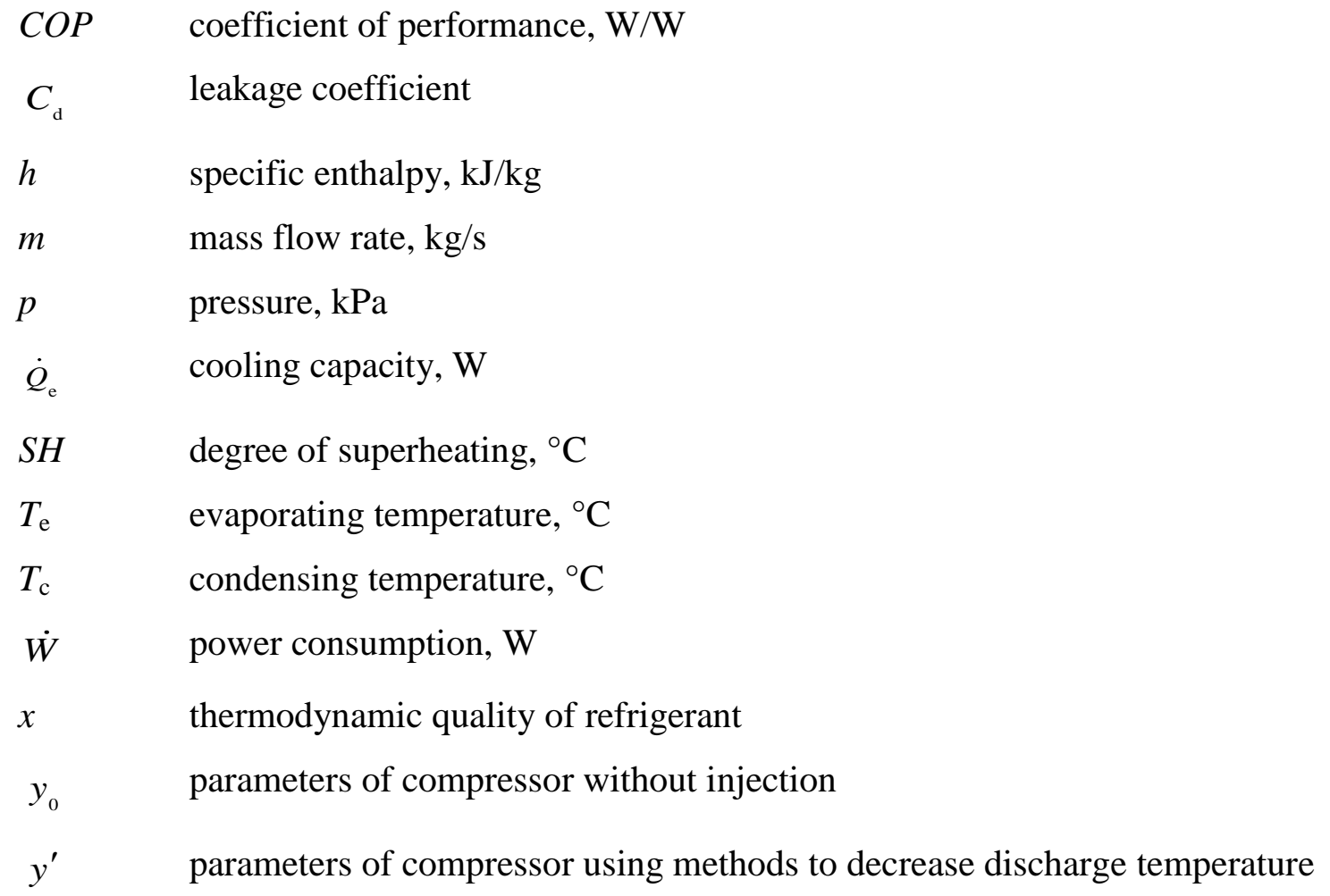




$\begin{array}{ll}\text { inj } & \text { injection } \\ \text { int } & \text { intermediate } \\ \text { out } & \text { outlet } \\ \text { suc } & \text { suction }\end{array}$




\section{Introduction}

\section{1. $R 32$ as an alternative refrigerant}

Hydrochlorofluorocarbons (HCFCs), such as R22, are widely used in vapor compression refrigeration and air conditioning systems due to their high energy efficiency ratio (Yang and $\mathrm{Wu}, 2013)$. However, the transition from HCFCs is underway for environmental protection pursuant to the Montreal Protocol, and the increasingly stringent global restriction of greenhouse gas emission accelerates the schedule. Hydrofluorocarbons (HFCs) are the leading replacement for HCFCs in refrigeration and air-conditioning systems (Bolaji and Huan, 2013). Mixtures of HFCs, such as R410A and R407C, are being used in some countries to replace R22 (Calm and Domanski, 2004), while the global warming potential (GWP) of R410A (GWP=2088) and R407C (GWP=1770) are still relatively high.

Recently, R32 has been considered as an important alternative for use in small to medium capacity air conditioners and heat pumps by many countries. Although it is slightly flammable, it has advantages such as relatively low GWP (675) compared to R410A (2025) and favorable thermal properties (Pham and Rajendran, 2012). The latent heat of vaporization of $\mathrm{R} 32$ is about $40 \%$ higher than that of $\mathrm{R} 410 \mathrm{~A}$, which means R32 system requires a lower mass flow rate for same cooling capacity. But generally, high latent heat of vaporization refrigerant cause high discharge temperature (Yan et al., 2012). The discharge temperature of the $\mathrm{R} 32$ compressor is typically approximately $20^{\circ} \mathrm{C}$ higher than that with $\mathrm{R} 410 \mathrm{~A}$ in standard air conditioning condition $\left(T_{\mathrm{e}}=7.2^{\circ} \mathrm{C}, T_{\mathrm{c}}=54.4^{\circ} \mathrm{C}\right.$ and $\left.\mathrm{SH}=11.1^{\circ} \mathrm{C}\right)$. The excess may be over $30^{\circ} \mathrm{C}$ in severe conditions such as air conditioner 
with ambient temperature higher than $45^{\circ} \mathrm{C}$ and heat pump with ambient temperature lower than $-15^{\circ} \mathrm{C}$.

The extremely high discharge temperature of R32 compressor reduces the reliability of system operation due to the possibility of lubricating oil degradation, and leads to the limited operating envelope of R32 compressors. The increased discharge temperature of R32 compressor becomes the main barrier affecting the wide and quick adoption.

\subsection{Methods to decrease discharge temperature}

Various technologies have been found to be conducive to decreasing discharge temperature. Among them, two-phase suction, liquid injection and two-phase injection are considered to be promising for wide application in compressors with low sensitivity to wet compression, such as scroll compressors.

Refrigerant drawn into a compressor is usually a vapor with a certain superheated degree to avoid slugging problems. The discharge temperature of the compressor can be reduced by minimizing superheating degree, however, the decrease is insufficient in severe conditions. When the suction refrigerant quality is lower than 1.0, indicating two-phase suction, the process in the compressor chamber could be wet compression. In this situation, the discharge temperature would be sharply decreased (Dutta et al., 1996). Yajima et al. (2011) found that the discharge temperature can be controlled within $135^{\circ} \mathrm{C}$ with the suction quality of 0.93 in a high-side R32 scroll compressor. Cao et al. (2009) conducted an experiment to investigate the influence of liquid injection into the suction line on the performance of a heat pump water heater utilizing R22 as refrigerant. It is found that the 5\% ratio of liquid injection into the suction line could reduce the discharge 
temperature by above $10^{\circ} \mathrm{C}$, whereas the heating capacity decreases $5 \%$ and power consumption increases less than $1.5 \%$.

Liquid refrigerant injection is also a good option to avoid excessively high discharge temperature (Xu et al., 2011). Liquid injection is intended to protect the compressor by providing adequate cooling. Dutta et al. (2001) theoretically and experimentally investigated the influence of liquid refrigerant on performance of a R22 high-side scroll compressor, and found that the oil temperature decreased with increasing injection ratio and lead to a slight improvement in performance. Winandy et al. (2002) studied the effects of liquid injection on the discharge temperature of a R22 compressor and their results showed that the discharge temperature decreased linearly with injection ratio. For each percentage of liquid injection, discharge temperature decreased by approximately $1.2^{\circ} \mathrm{C}$. Cho et al. (2003) studied the influence of liquid injection on an inverter-driven low-side scroll compressor at different compressor frequencies. It was concluded that liquid injection under high frequency was very effective at attaining higher performance and reliability of the compressor, whereas injection under low frequency showed some disadvantages with respect to compressor power, capacity, and adiabatic efficiency due to high leakage through the gap in the scroll wrap.

Gas refrigerant injection is an important technique to improve the cooling capacity and COP (Navarro et al., 2013). Wang et al. (2007) compared the influences of gas injection and liquid injection on system performance. It was revealed that gas injection increased the system performance significantly and that liquid injection had limited influence. A number of studies on gas injection have also proven that gas injection provides significant enhancement in capacity and COP (Guo et al., 2012; Xu et al., 2013a; Xu et 
al., 2013b; Bell et al., 2013). In addition, gas injection demonstrates a decrease in discharge temperature (Xu et al., 2011), though the cooling effect provided by vapor refrigerant is limited. Two-phase injection is able to offer more effective cooling during compression. Park et al. (2002) compared the discharge temperature of two-phase injection with that of no injection in a low-side R22 compressor, and found that the discharge temperature can be reduced by $10-20^{\circ} \mathrm{C}$ with the injected refrigerant quality of 0.9. Wang et al. (2009a) also analyzed the effects of injection enthalpy on a R22 scroll compressor. It was found that the indicated efficiency increased with the decrease of injection enthalpy, which was attributed to decrease in the inner leakage and effects on the under- or over-compression loss.

\subsection{Objectives of this work}

Although there are some previous research separately conducted on two-phase suction, liquid injection, or two-phase injection, the comparative study of these three method on R32 scroll compressor is still lack. The objective of this study is to comparatively investigate the effectiveness of the three methods to decrease the discharge temperature and their effects on performance of the R32 scroll compressor.

Fig. 1 (a c) shows the schematics and $p-h$ diagrams of the injection cycles for three methods: (1) two-phase suction, which can be achieved by either directly controlling the opening of the expansion valve or injecting liquid refrigerant into the suction line (the latter is used in this study); (2) liquid injection, by injecting liquid refrigerant at the outlet of the condenser into the compression pocket through a control valve; (3) two-phase injection, by injecting two-phase refrigerant into the compression pocket, an internal heat 
exchanger is settled in the outlet of the condenser and a liquid injection line in added to the system, vapor generated in the internal heat exchanger and liquid from liquid injection line are mixed and then injected into compressor.

Fig. 1. Schematics and p-h diagrams of the three methods.

\section{Model development and validation}

The scroll compressor offers low vibration and noise level, high efficiency and high reliability, and has become increasingly popular in the fields of refrigeration and air-conditioning (Gravesen and Henriksen, 2001). Wet compression might occur in all three methods studied and slugging is a common concern. Fortunately, the scroll compressor has been widely recognized as the most suitable compressor type for application of refrigerant injection technology, as it is less sensitive to slugging problems (Liu and Soedel, 1994).

Owing to possible damage to compressor and large expense caused by experimental research, this study is carried out by numerical simulation based on the validated model of the R32 scroll compressor.

\subsection{Model development}

The refrigerant injection process is a continual parameter-varying and time-varying "adiabatic throttling + isobaric mixing" process (Wang et al., 2008). To investigate the effects of refrigerant injection on the whole process of the compressor, a distributed parameter model of the scroll compressor is applied (Wang et al., 2005 and 2008). This model includes the suction, compression and discharge processes. The refrigerant leakage, both in radial direction and flank direction, and the refrigerant injection have been 
considered. Besides, the heat transfer of refrigerant with suction tube, the scroll wall, motor, mechanical components and shell have been calculated. Fig. 2 shows the flow chart of the distributed parameter model for scroll compressor. Because the time scale of compressor is much smaller than that of the refrigeration system, the time-averaged outputs of the dynamic compressor model are used to calculate the cycle performance (Wang et al., 2009b).

The leakage coefficient $C_{\mathrm{d}}$ in scroll compressor is affected by many factors such as lubricating performance of oil and operating conditions. However, these influence are usually neglected in most compressor models. In this study, the simulated conditions vary in a large range and the lubricating performance varies greatly from condition to condition. To generally involve these effects in the model, the leakage coefficient is fitted as a function of compression ratio $\varepsilon$ (equals to $p_{\text {dis }} / p_{\text {suc }}$ ) based on 28 test results on the studied compressor, as shown in equation (1):

$$
C_{\mathrm{d}}=\left\{\begin{array}{cc}
0.2772 & \varepsilon \leq 2.72 \\
0.003666 \varepsilon^{4}-0.0844 \varepsilon^{3}+0.6763 \varepsilon^{2}-2.0917 \varepsilon+2.4609 & 2.72<\varepsilon<8.00 \\
0.8136 & \varepsilon \geq 8.00
\end{array}\right.
$$

It should be noticed that this equation of leakage coefficient is just fit for the specified compressor studied in this research. For the other compressors, the expression will need modification based on the test results of the research compressors.

In addition, the variation of motor efficiency in different conditions has been taken into account. Fig. 3 shows the motor efficiency variation with compressor power input according to the motor catalog.

Fig. 2. Flow chart of distributed parameter model for scroll compressor. 
Fig. 3. Variation of motor efficiency with compressor power input.

\subsection{Model validation}

The model has to be validated with a variety of conditions before it is employed in performance prediction of the R32 scroll compressor. The compressor chosen for this study is a low-side (suction gas cooled motor) scroll compressor. Table 1 presents the parameters of the compressor.

The experimental data provided by manufacture is obtained on a standard test plant with high accuracy instruments, the uncertainties of cooling capacity and power consumption are $2.0 \%$ and $1.5 \%$ respectively. Both conditions without refrigerant injection and those with liquid refrigerant injection are validated, as shown in Fig. 4. It can be concluded that the predicted results agree well with experimental results, with the relative errors of cooling capacity and power consumption within $6 \%$ and $9 \%$, respectively. The average deviations of cooling capacity and power consumption are $1.4 \%$ and $2.6 \%$, respectively. The results indicate that the model is capable of predicting performance of the R32 scroll compressor.

Table 1 Parameters of the scroll compressor.

Fig. 4. Comparison of experimental and simulated results.

\section{Methodology}

To investigate the influences of the three methods on compressor performance, the modified distributed parameter model is applied to simulate the performance of the R32 scroll compressor in various conditions. The subcooling degree at the condenser outlet 
and superheating degree at the evaporator outlet are maintained at $3{ }^{\circ} \mathrm{C}$ and $5^{\circ} \mathrm{C}$, respectively.

During the evaluation, the performance of the R32 scroll compressor without injection is used as the baseline, and the relative performance is defined in equation (2):

$$
\varphi=\frac{y^{\prime}}{y_{0}}
$$

Where $\varphi$ is the relative performance, $y_{0}$ represents the parameters of the R32 scroll compressor without discharge temperature control, and $y^{\prime}$ represents the parameters of the R32 scroll compressor using methods to decrease discharge temperature. The injection ratio is defined as the injected refrigerant divided by the mass flow rate in the evaporator, as given in equation (3):

$$
\alpha=\frac{m_{\mathrm{inj}}}{m_{\mathrm{suc}}}
$$

where $m_{\mathrm{inj}}$ is the injected mass flow rate, and $m_{\text {eva }}$ is the mass flow rate in evaporator.

To describe the state of suction refrigerant and injected refrigerant, the thermodynamic quality is adopted (Kandlikar, 1999). In the two-phase region, the thermodynamic quality equals to the mass quality. But in the superheated vapor region and subcooled liquid region, the thermodynamic quality can more clearly represent the refrigerant state.

$$
x=\frac{h-h_{1}}{h_{\mathrm{g}}-h_{1}}
$$

where $h$ is the enthalpy of refrigerant, $h_{1}$ and $h_{\mathrm{g}}$ are the enthalpy of saturated liquid and gas refrigerant, respectively. 
Especially in two-phase injection, the intermediate pressure is an important parameter affecting the injected mass flow rate and the heat transfer in internal heat exchanger. To make the conclusions more general, the relative intermediate pressure is defined as the ratio of the intermediate pressure to the geometric mean value of suction pressure and discharge pressure of compressor (Ma and Chai, 2004), which is given by equation (5):

$$
\beta=\frac{p_{\text {int }}}{\sqrt{p_{\text {suc }} \cdot p_{\text {dis }}}}
$$

where $p_{\text {int }}$ is the intermediate pressure, $p_{\text {suc }}$ is the suction pressure and $p_{\text {dis }}$ is the discharge pressure.

In this research, the effects of different methods on the theoretical system performance is evaluated, which means the evaporating temperature and the condensing temperature keep same under the same working condition. It's the important basis of further system performance evaluation.

The cooling capacities of three cycles can be calculated by equation (6):

$$
\dot{Q}_{\mathrm{e}}=m_{\text {eva }}\left(h_{\text {eva,out }}-h_{\text {eva,in }}\right)
$$

It need be mentioned that, in the two-phase suction cycle and liquid injection cycle, the specific enthalpy at the inlet of the evaporator $h_{\text {eva,in }}$ equals to the specific enthalpy at the outlet of the condenser $h_{\text {con,out }}$, but for the two-phase injection cycle, the refrigerant is further subcooled in the internal heat exchanger and $h_{\text {eva,in }}$ is calculated as following:

$$
h_{\text {eva,in }}=h_{\text {con,out }}-m_{\text {inj }}\left(h_{\text {inj }}-h_{\text {con,out }}\right) / m_{\text {eva }}
$$




\section{Results and discussion}

As illuminated in Fig.5, the operating envelope of scroll compressor is affected by many factors, such as mechanical structure deformation, lubricants pyrolysis in high temperature, instability of the scroll, overload of the motor, performance degradation of the lubricating system, largely decrease of the thermodynamic performance, and so on. The R32 has a close thermodynamic properties with R410A but the discharging temperature. So the well-developed R410A scroll compressor will work well for the R32 in the operating envelope except in the region with high discharge temperature. Fig.5 presents the test operating envelopes of the same scroll compressors using R32 and $\mathrm{R} 410 \mathrm{~A}$, respectively. It is obvious that operating envelope of R32 compressor is largely narrowed by approximately $10^{\circ} \mathrm{C}$ in condensing temperature. So, by the effective control of the discharge temperature, the R410A compressor can be used in the R32 applications, which means the operating envelope of the R32 scroll compressor can be same as R410A scroll compressor. So this work mainly investigates the effect of different methods and parameters on envelope lines controlled by the discharge temperature. The evaporating temperature range for the adopted compressor is from $-20^{\circ} \mathrm{C}$ to $15^{\circ} \mathrm{C}$ and condensing temperature ranging is from $25^{\circ} \mathrm{C}$ to $65^{\circ} \mathrm{C}$.

Fig. 5. Limiting factors and operating envelopes of the scroll compressor using R32 and R410A.

\subsection{Two-phase suction}

In two-phase suction, the liquid refrigerant from the condenser outlet is directly injected into the suction line to adjust the enthalpy of the suction refrigerant. By lowering the suction thermodynamic quality to a certain degree, within the scroll compressor's ability 
to handle liquid slugging, it is possible to reduce the discharge temperature of R32 compressor.

\subsubsection{Effects on discharge temperature and performance}

Fig. $6(\mathrm{a} \sim \mathrm{d})$ illustrates the variations of discharge temperature, injection ratio, relative cooling capacity and relative power consumption of R32 scroll compressors with various suction qualities. The evaluation is conducted under three operating conditions with the condensing temperature of $40^{\circ} \mathrm{C}, 50^{\circ} \mathrm{C}$ and $60^{\circ} \mathrm{C}$, respectively, and the evaporating temperature is maintained at $-5^{\circ} \mathrm{C}$. It is clearly observed that the discharge temperature decreases almost linearly with the decrease of suction refrigerant thermodynamic quality. In average, discharge temperature decreases by approximately $7^{\circ} \mathrm{C}, 14^{\circ} \mathrm{C}$ and $22^{\circ} \mathrm{C}$ by lowering suction thermodynamic quality to $1,0.98$ and 0.96 , respectively. With the suction thermodynamic quality going down, the two-phase suction obtains greater potential in decreasing discharge temperature, but it shows a limited impact on cooling capacity. The cooling capacity increases slightly at first until a suction thermodynamic quality of around 0.98 and decreases afterwards with the maximum deviation no more than $1.5 \%$. In addition, the power consumption shows minimal difference in conditions with the suction thermodynamic quality higher than 0.98 . With further lowering of suction thermodynamic quality, the gas refrigerant compression in the compression pocket partially becomes two-phase refrigerant compression and the power consumption continuously decreases.

However, it must be mentioned that two-phase suction in the low-side scroll compressor probably operates in unsteady state and could reduce the reliability of compressor. When the thermodynamic quality of suction refrigerant is lower than a certain degree, the 
refrigerant is still two-phase after the motor heating (Dash line in Fig.6). In this situation, the saturated gas will be sucked into the scroll and the liquid will remain in the casing and accumulates. The compressor will keep a steady state until the liquid level reaches the suction port of the scroll and the liquid refrigerant is sucked into the scroll pocket in a large amount, which is quite dangerous due to possible liquid slugging. Moreover, the accumulation of the liquid refrigerant in the case will lead to amount of refrigerant dissolving into the oil, which will largely decrease the lubricating effect of the oil and increase the possibility of mechanical failure. To reduce the risks, it is better to keep the suction refrigerant thermodynamic quality higher than a safety level in the low-side compressor.

Fig. 6. Effects of suction thermodynamic quality on the compressor performance $(\mathrm{Te}=$ $-5^{\circ} \mathrm{C}$ ).

\subsubsection{Operating envelope}

To decide the operating envelope of the R32 scroll compressor using different discharge temperature control methods, 72 conditions are simulated with the step of $5^{\circ} \mathrm{C}$ for evaporating temperature and condensing temperature, and bilinear interpolation is used to generate the contour map for discharge temperature. The conditions with discharge temperature higher than $135^{\circ} \mathrm{C}$ are considered to be unacceptable and hence outside the operating envelope.

Fig. 7 shows the operating envelopes of R32 scroll compressor with different suction qualities. The envelope of suction refrigerant with superheating of $5^{\circ} \mathrm{C}$ refers to the envelope of the R32 scroll compressor without injection. For compressors with suction qualities maintained at 1.00, 0.95 and 0.90 , the envelopes expand by approximately $5^{\circ} \mathrm{C}$, 
$10^{\circ} \mathrm{C}$ and $20^{\circ} \mathrm{C}$ in condensing temperature over that without injection. In general, with lower suction thermodynamic quality, the R32 compressor achieves a wider operating envelope. To expand the R32 envelope to that as large as R410A envelope, the suction thermodynamic quality should be lowered to 0.95 .

Fig. 7. Operating envelopes of R32 scroll compressor with different suction qualities.

\subsection{Liquid injection}

In liquid injection, the liquid refrigerant from the condenser outlet is injected into compression pocket. As the specific enthalpy of liquid refrigerant is much lower than that of refrigerant in compression pocket, it is possible to provide internal cooling and reduce the discharge temperature of compressor.

\subsubsection{Effects on discharge temperature and performance}

Fig. $8(\mathrm{a} \sim \mathrm{d})$ demonstrates the variations of discharge temperature, relative cooling capacity, relative power consumption and relative COP of R32 scroll compressors with various injection ratios. With the increase in injection ratio, the discharge temperature decreases dramatically. For each percentage of liquid injection increased, discharge temperature decreased by $2.1-2.8^{\circ} \mathrm{C}$, which is higher than the decrease in the $\mathrm{R} 22$ compressor (Winandy et al., 2002 and Cho et al., 2003). As the latent heat of R32 is high, R32 compressor enjoys more benefits in decreasing discharge temperature than compressors utilizing other refrigerants. It is noticed that cooling capacity shows a slight enhancement of no more than $3 \%$ with the increasing injection ratio, which is mainly due to the reduction of inner leakage caused by the decreasing refrigerant pressure in compression pocket. The power consumption shows some decrease with the increasing 
injection ratio. The reason is also relevant to the lower refrigerant pressure in pocket and less leakage in wet compression. Hence, the COP is improved by liquid injection by no more than $6 \%$.

Fig. 8. Effects of liquid injection ratio on the compressor performance $\left(\mathrm{Te}=-5^{\circ} \mathrm{C}\right)$.

\subsubsection{Operating envelope}

Fig. 9 shows the operating envelopes of R32 scroll compressor with different injection ratios. For compressors with injection ratios of 5\%,10\% and $20 \%$, the envelopes expand by approximately $7^{\circ} \mathrm{C}, 12^{\circ} \mathrm{C}$ and $20^{\circ} \mathrm{C}$ in condensing temperature over that without injection. The internal cooling provided by liquid refrigerant is very effective in decreasing discharge temperature. With the injection ratio of $10 \%$, the envelope is able to cover most of the conditions with high compression ratios. On the whole, with an $8 \%$ injection ratio, liquid injection is able to guarantee the steady operation of R32 scroll compressor in the same operating envelope as the R410A scroll compressor.

Fig. 9. Operating envelopes of R32 scroll compressor with different injection ratios.

\subsection{Two-phase injection}

In the two-phase injection, the refrigerant is injected into the compression pocket after heat exchange in the internal heat exchanger. The injected refrigerant could be two-phase or superheated gas. The injected refrigerant could also provide internal cooling for the compressor and thereby decrease the discharge temperature. 


\subsubsection{Effects on discharge temperature and performance}

Both the intermediate pressure and the specific enthalpy of injected refrigerant affect the cooling by two-phase injection. The intermediate pressure influences the mass flow rate injected into compression pocket, whereas the specific enthalpy determines the cooling intensity by injected refrigerant. As illuminated in Fig.1(c), the expansion valve 2 can control the intermediate pressure and the opening of the control valve can control the specific enthalpy of refrigerant at the injection port.

Fig. 10 presents the variations of discharge temperature, injection ratio, relative cooling capacity and relative $\mathrm{COP}$ of $\mathrm{R} 32$ scroll compressors with gas injection $\left(\mathrm{SH}_{\mathrm{inj}}=5^{\circ} \mathrm{C}\right)$ and two-phase injection $\left(x_{\mathrm{inj}}=0.8\right)$ with various relative intermediate pressures. In general, the decreases in discharge temperature by gas injection are quite limited and the decreases by two-phase injection are very effective $\left(7.4^{\circ} \mathrm{C}, 11.2^{\circ} \mathrm{C}\right.$ and $20.8^{\circ} \mathrm{C}$ for condensing temperature $40^{\circ} \mathrm{C}, 50^{\circ} \mathrm{C}$ and $60^{\circ} \mathrm{C}$, respectively). The injection ratio increases with the increase of intermediate pressure, but two-phase injection obtains higher injection ratio than gas injection under the same intermediate pressure. Two-phase injection and gas injection achieve similar enhancements both in cooling capacity and $\mathrm{COP}$, and the enhancements become more obvious with higher injection ratio. Overall, the enhancements of cooling capacity by two-phase injection could reach up to approximately $8 \%, 11 \%$ and $15 \%$ in conditions with the condensing temperatures of $40^{\circ} \mathrm{C}, 50^{\circ} \mathrm{C}$ and $60^{\circ} \mathrm{C}$, and the maximum improvements in $\mathrm{COP}$ are $0.8 \%, 2.6 \%$ and $6.7 \%$.

Fig. 10. Effects of injected refrigerant states on the compressor performance $\left(\mathrm{Te}=-5^{\circ} \mathrm{C}\right)$. 
Fig. 11 shows the variations of discharge temperature, injection ratio, relative cooling capacity and relative COP of R32 scroll compressors with various qualities of injected refrigerant at the relative intermediate pressure of 1.0. With the decrease of injected refrigerant thermodynamic quality, more liquid refrigerant is injected into the compression pocket and provides more internal cooling for compressor. The decreases in discharge temperatures reach up to $12.4^{\circ} \mathrm{C}, 17.6^{\circ} \mathrm{C}$ and $24.6^{\circ} \mathrm{C}$ in conditions with the condensing temperatures of $40^{\circ} \mathrm{C}, 50^{\circ} \mathrm{C}$ and $60^{\circ} \mathrm{C}$ with the injected refrigerant thermodynamic quality of 0.7 . It is found that two-phase injection could remarkably enhance the cooling capacity as gas injection, but the enhancement remains almost constant with the decrease of injected refrigerant thermodynamic quality. The reason is that the volume flow rate of gas refrigerant is far larger than that of liquid refrigerant in two-phase injection, and the flow resistance is mainly decided by gas flow rate. Under the same intermediate pressure, the gas refrigerant flow rate for different injection thermodynamic quality are almost the same, which decides the same enhancement in cooling capacity. The improvement in COP increases gradually due to the decrease of power consumption by wet compression, and the maximum improvements are $4.1 \%, 4.9 \%$ and $8.4 \%$ in conditions with the condensing temperatures of $40^{\circ} \mathrm{C}, 50^{\circ} \mathrm{C}$ and $60^{\circ} \mathrm{C}$.

Fig. 11. Effects of injected thermodynamic quality on the compressor performance

$$
\left(\beta=1.0 \text { and } \mathrm{Te}=-5^{\circ} \mathrm{C}\right) \text {. }
$$

\subsubsection{Operating envelope}

Fig. 12 shows the operating envelopes of R32 scroll compressor with different qualities of injected refrigerant at the relative intermediate pressure of 1.0. The discharge temperature is extremely high when evaporating temperature is lower than $-15^{\circ} \mathrm{C}$, the 
decrease in discharge temperature by gas injection becomes less effective. In general, the envelopes of compressors with the injected refrigerant thermodynamic quality of 1.0, 0.8 and 0.6 expand by about $5^{\circ} \mathrm{C}, 10^{\circ} \mathrm{C}$ and $17^{\circ} \mathrm{C}$ in condensing temperature over that without injection. With the thermodynamic quality of injected refrigerant at $0.8, \mathrm{R} 32$ scroll compressor is qualified to cover an envelope as large as that of the R410A compressor.

Fig. 12. Operating envelopes of R32 scroll compressor with various qualities of injected refrigerant $(\beta=1.0)$.

\subsection{Performance Comparison of the three methods in severe conditions}

All three methods show promising capabilities to decrease discharge temperature in severe conditions. To make a performance comparison of the three methods, four severe conditions with relatively high compression ratios are selected, as shown in Table 2. By various methods, the discharge temperature is maintained at $135^{\circ} \mathrm{C}$. The performance of liquid injection is used as the baseline.

Table 2 Four conditions selected for performance comparison of the three methods.

Fig. 13 shows the performance comparison of the R32 scroll compressor with different methods in four severe conditions. It is obvious that two-phase injection outperforms liquid injection and two-phase suction in both cooling capacity and COP. In average, the cooling capacity and COP of two-phase injection with a relative intermediate pressure of 1.0 are enhanced by $11.8 \%$ and $4.8 \%$, respectively, over liquid injection.

Fig. 13. Performance comparison of R32 scroll compressor with different discharge temperature-decreasing methods. 


\section{Conclusions}

$\mathrm{R} 32$ is an important alternative refrigerant, but its high discharge temperature has been the main barrier for wide and quick adoption. In this work, three techniques, namely, two-phase suction, liquid injection and two-phase injection, are comparatively investigated to decrease the discharge temperature of the R32 scroll compressor. Through comprehensive performance investigation, conclusions can be drawn as follows:

(1) All the three methods show excellent potential in decreasing the discharge temperature of the R32 scroll compressor.

(2) Two-phase injection outperforms liquid injection and two-phase suction in both cooling capacity and COP by $11.8 \%$ and $4.8 \%$, respectively.

(3) In two-phase injection, injected refrigerant thermodynamic quality has little influence on cooling capacity under the same intermediate pressure, because the effective flow rate of the gas refrigerant is almost same and the flow resistance is mainly decided by gas flow rate.

\section{Acknowledgements}

The authors are grateful for the financial support of the National Natural Science Foundation of China (Grant No. 51006059) and the National Science Foundation for Distinguished Young Scholars of China (Grant No.51125030), and we express our thanks for the support of Commercial Scroll Compressor, Danfoss (Tianjin) Ltd. 


\section{References}

Bolaji, B.O., Huan, Z., 2013. Ozone depletion and global warming: Case for the use of natural refrigerant - a review. Renew Sust Energ Rev 18, 49-54.

Bell, I., Groll, E., Braun, J., Horton, W.T., 2013. Simulation of a cold climate heat pump furnished with a scroll compressor with multiple injection lines, International Conference on Compressors and their Systems 2013.

Calm, J.M., Domanski, P., 2004. R-22 replacement status. ASHRAE journal 46, 29-39.

Cao, F., Fei, J.Y., Xing, Z.W., Li, L.S., 2009. Study on performance of a heat pump water heater using suction stream liquid injection. Appl Therm Eng 29, 2942-2948.

Cho, H., Chung, J.T., Kim, Y., 2003. Influence of liquid refrigerant injection on the performance of an inverter-driven scroll compressor. Int J Refrig 26, 87-94.

Dutta, A., Yanagisawa, T., Fukuta, M., 1996. A study on compression characteristic of wet vapor refrigerant. Proceedings of International Compressor Engineering Conference at Purdue.

Dutta, A.K., Yanagisawa, T., Fukuta, M., 2001. An investigation of the performance of a scroll compressor under liquid refrigerant injection. Int J Refrig 24, 577-587.

Guo, W., Ji, G., Zhan, H., Wang, D., 2012. R32 Compressor for Air conditioning and Refrigeration applications in China. Proceedings of 14th International Refrigeration and Air Conditioning Conference at Purdue University.

Gravesen, J., Henriksen, C., 2001. The geometry of the scroll compressor. Siam Review 43, 113-126.

Kandlikar S G. Handbook of phase change: boiling and condensation[M]. CRC Press, 1999. 
Liu, Z., Soedel, W., 1994. An investigation of compressor slugging problems. Proceedings of International Compressor Engineering Conference at Purdue Ma, G.-y., Chai, Q.-h., 2004. Characteristics of an improved heat-pump cycle for cold regions. Appl Energ 77, 235-247.

Navarro, E., Redon, A., Gonzalvez-Macia, J., Martinez-Galvan, I.O., Corberan, J.M., 2013. Characterization of a vapor injection scroll compressor as a function of low, intermediate and high pressures and temperature conditions. Int J Refrig 36, 1821-1829.

Park, Y.C., Kim, Y., Cho, H., 2002. Thermodynamic analysis on the performance of a variable speed scroll compressor with refrigerant injection. Int J Refrig 25, 1072-1082.

Pham, H.M., Rajendran, R., 2012. R32 And HFOs As Low-GWP Refrigerants For Air Conditioning. Proceedings of 14th International Refrigeration and Air Conditioning Conference at Purdue University.

Wang, B., Li, X., Shi, W., 2005. A general geometrical model of scroll compressors based on discretional initial angles of involute. International journal of refrigeration 28, 958-966.

Wang, B.L., Li, X.T., Shi, W.X., Yan, Q.S., 2007. Design of experimental bench and internal pressure measurement of scroll compressor with refrigerant injection. Int $\mathbf{J}$ Refrig 30, 179-186.

Wang, B.L., Shi, W.X., Li, X.T., 2009a. Numerical analysis on the effects of refrigerant injection on the scroll compressor. Appl Therm Eng 29, 37-46.

Wang, B.L., Shi, W.X., Han, L.J., Li, X.T., 2009b. Optimization of refrigeration system with gas-injected scroll compressor. Int J Refrig 32, 1544-1554. 
Wang, B.L., Shi, W.X., Li, X.T., Yan, Q.S., 2008. Numerical research on the scroll compressor with refrigeration injection. Appl Therm Eng 28, 440-449.

Winandy, E.L., Lebrun, J., 2002. Scroll compressors using gas and liquid injection: experimental analysis and modelling. Int J Refrig 25, 1143-1156.

Xu, S.X., Ma, G.Y., Liu, Q., Liu, Z.L., 2013a. Experiment study of an enhanced vapor injection refrigeration/heat pump system using R32. Int J Therm Sci 68, 103-109.

Xu, X., Hwang, Y., Radermacher, R., 2013b. Performance comparison of R410A and R32 in vapor injection cycles. Int J Refrig 36, 892-903.

Xu, X., Hwang, Y.H., Radermacher, R., 2011. Refrigerant injection for heat pumping/air conditioning systems: Literature review and challenges discussions. Int J Refrig 34, 402-415.

Yan, C., Xu, H., Watts, S., Ginies, P., 2012. R32 Scroll Compressors Technology. Proceeding of International Compressor Engineering Conference at Purdue.

Yajima Ruzaburo, Yoshimi Atsushi, Piao Chuncheng, 2011. Measures to reduce the discharge temperature of R32 compressor. Refrigeration and Air-conditioning 11, 60-64 (in Chinese).

Yang, Z., Wu, X., 2013. Retrofits and options for the alternatives to HCFC-22. Energy 59, $1-21$. 

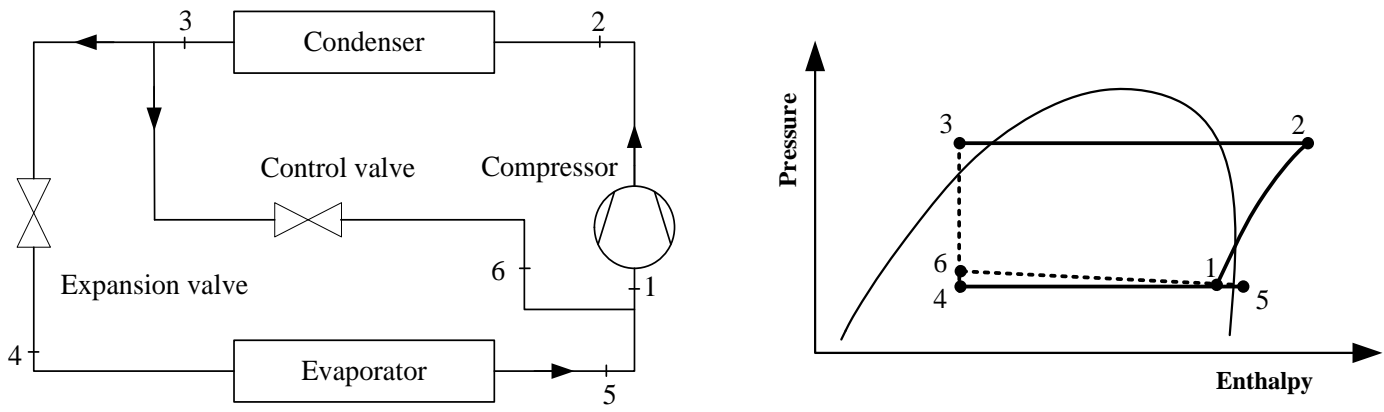

a) Two-phase suction
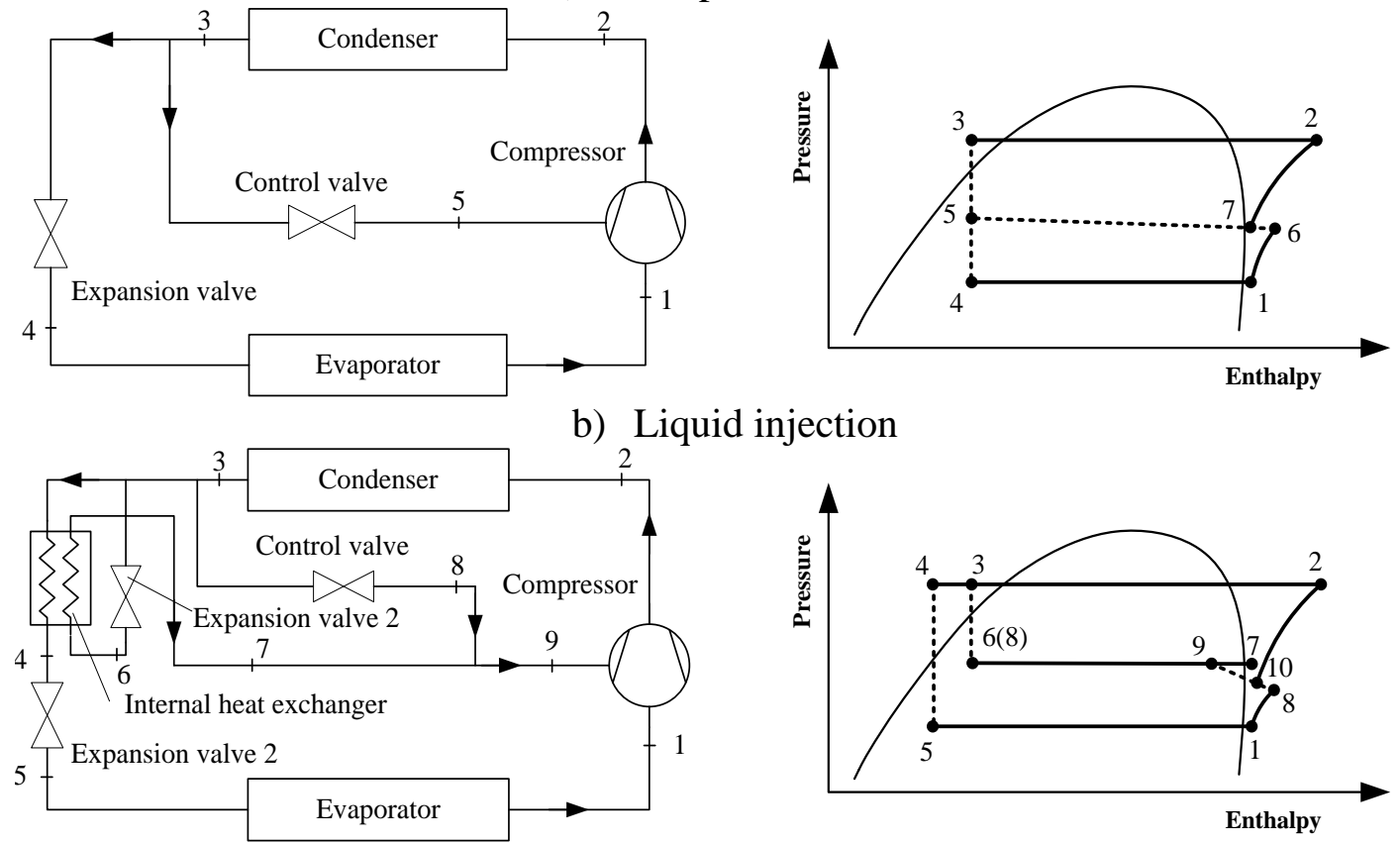

c) Two-phase injection

Fig. 1. Schematics and $\mathrm{p}-\mathrm{h}$ diagrams of the three methods. 


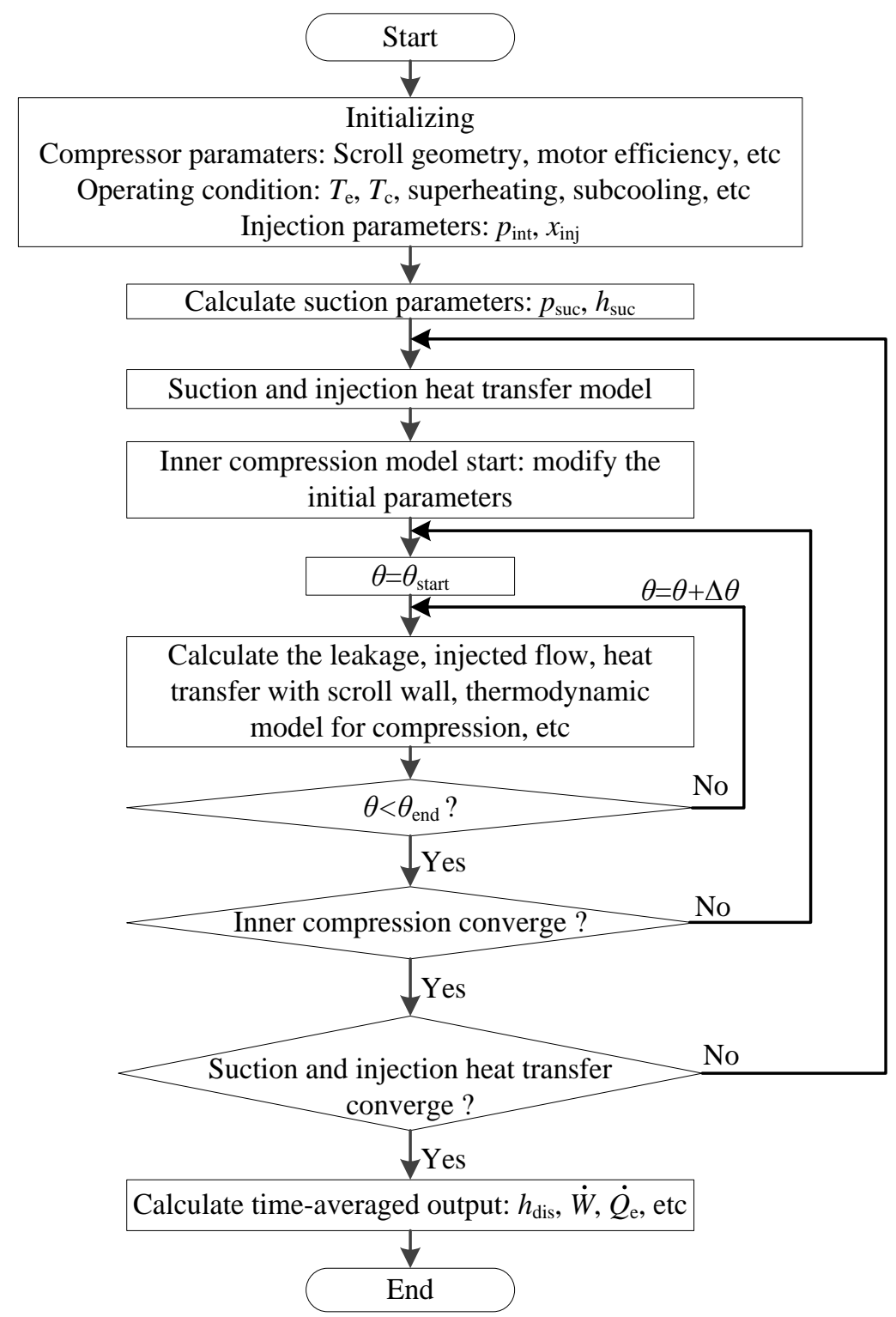

Fig. 2. Flow chart of distributed parameter model for scroll compressor. 


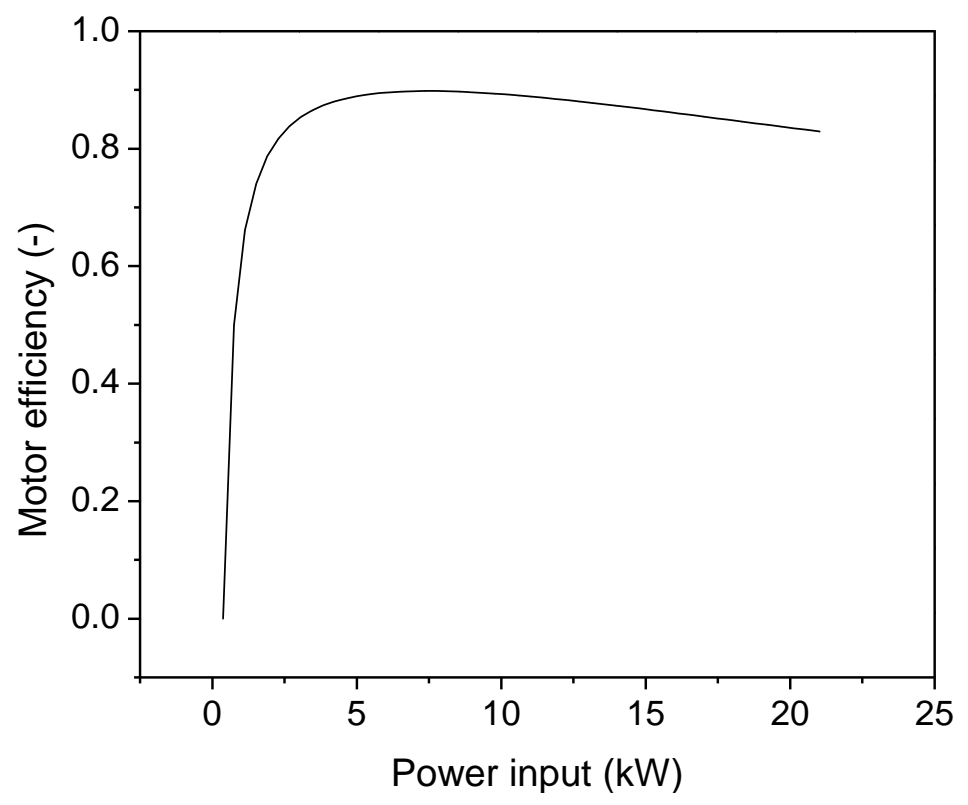

Fig. 3. Variation of motor efficiency with compressor power input. 


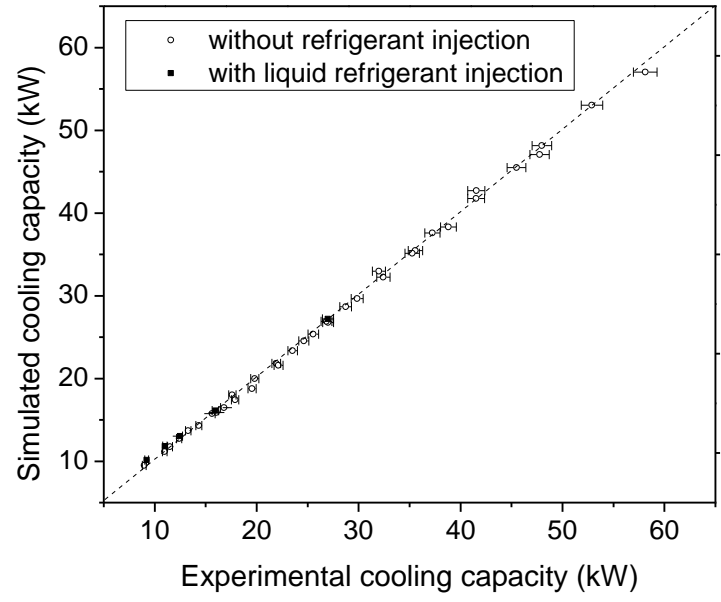

a) Cooling capacity

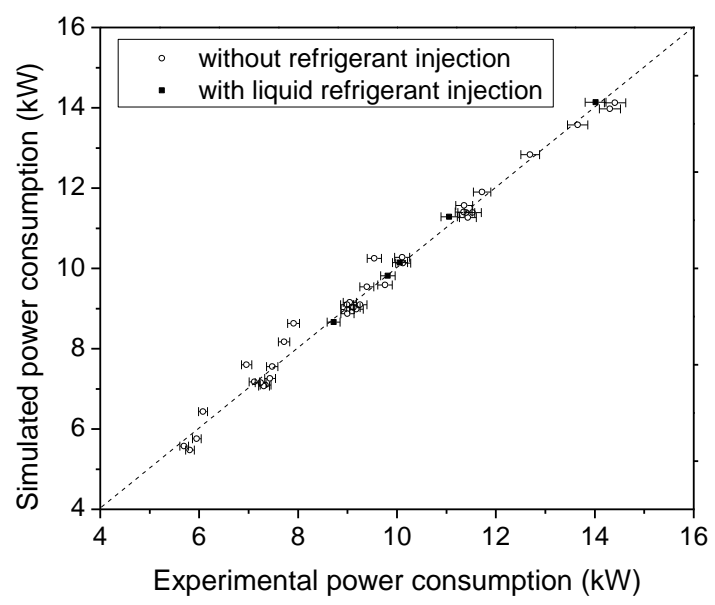

b) Power consumption

Fig. 4. Comparison of experimental and simulated results. 


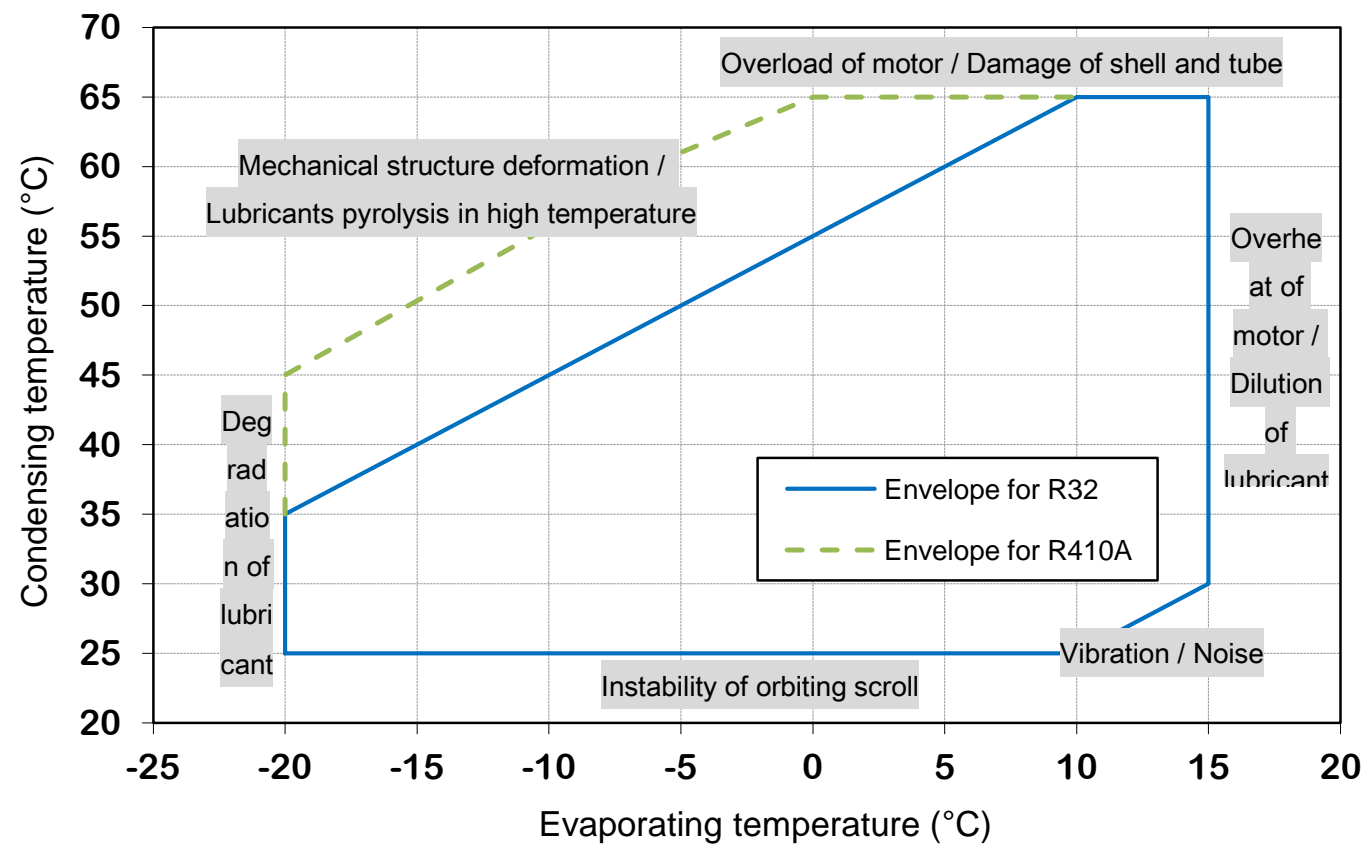

Fig. 5. Limiting factors and operating envelopes of the scroll compressor using R32 and R410A. 

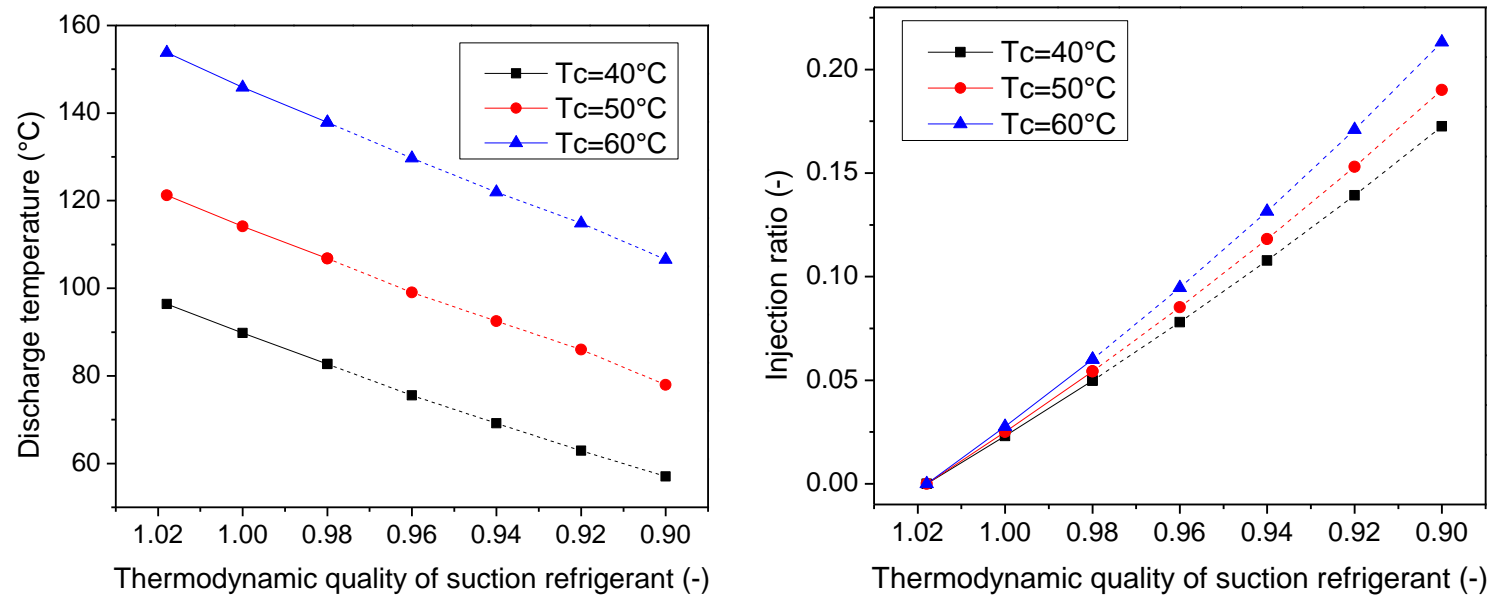

a) discharge temperature

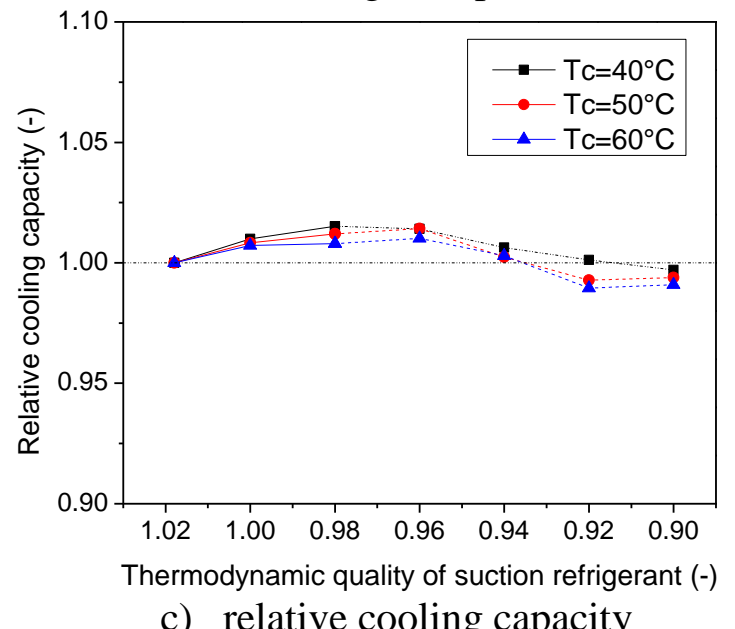

b) injection ratio

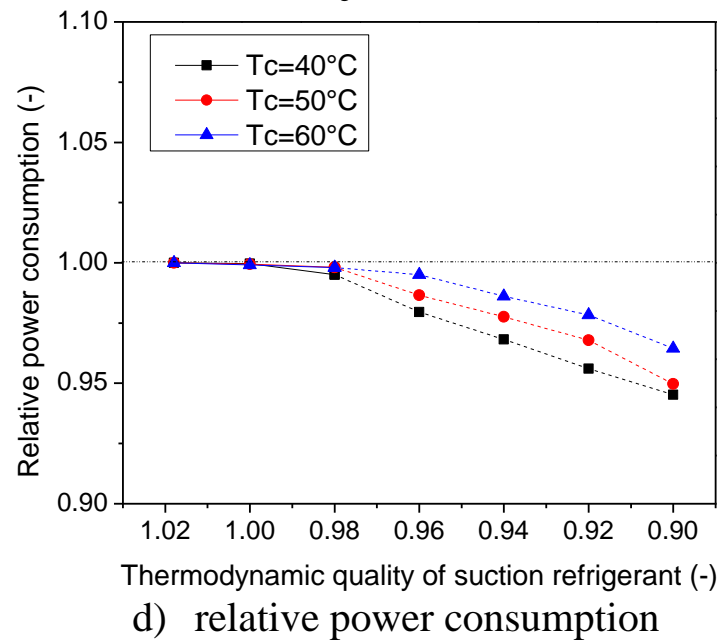

Fig. 6. Effects of suction thermodynamic quality on the compressor performance $(\mathrm{Te}=$ $\left.-5^{\circ} \mathrm{C}\right)$. 


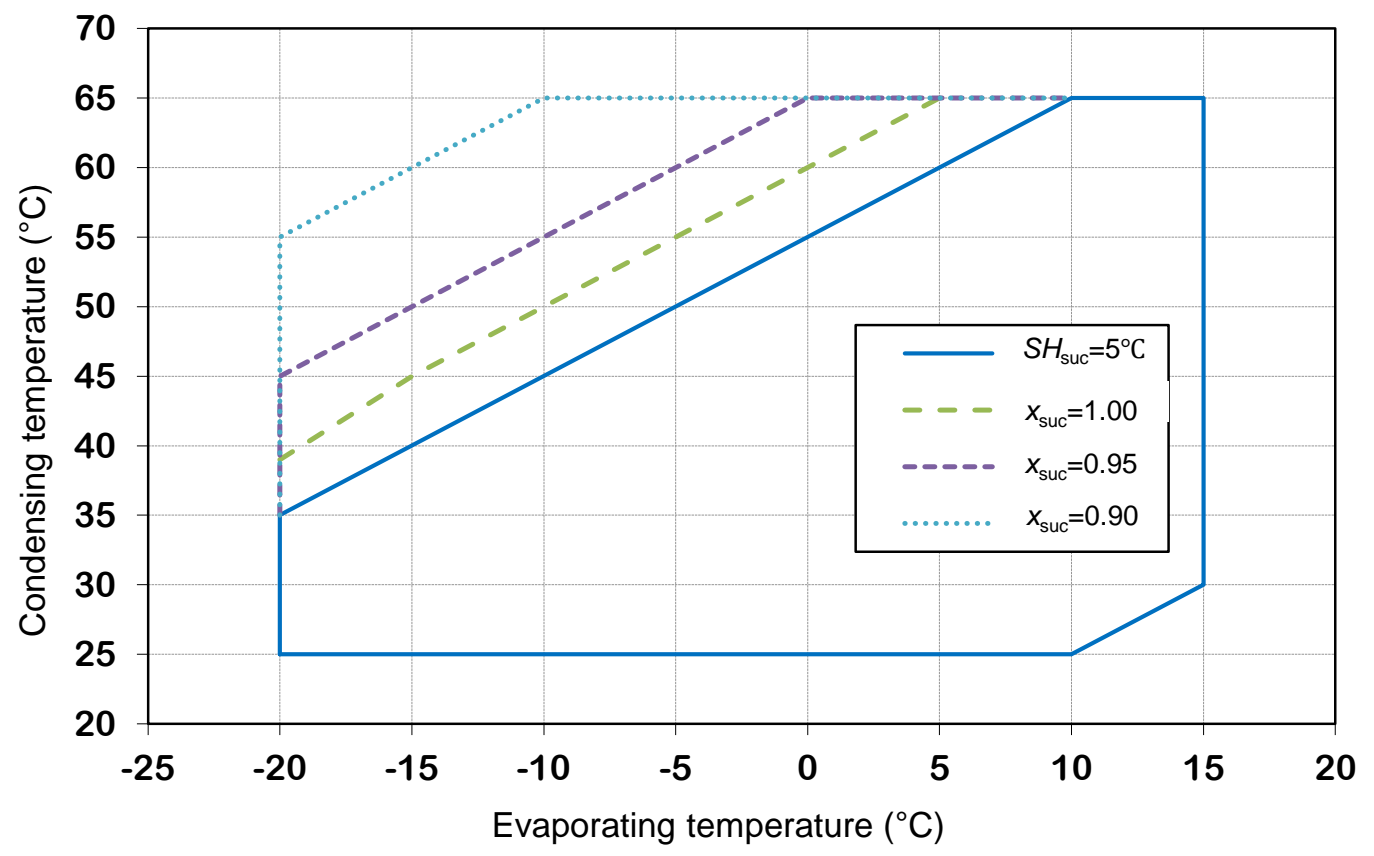

Fig. 7. Operating envelopes of R32 scroll compressor with different suction qualities. 

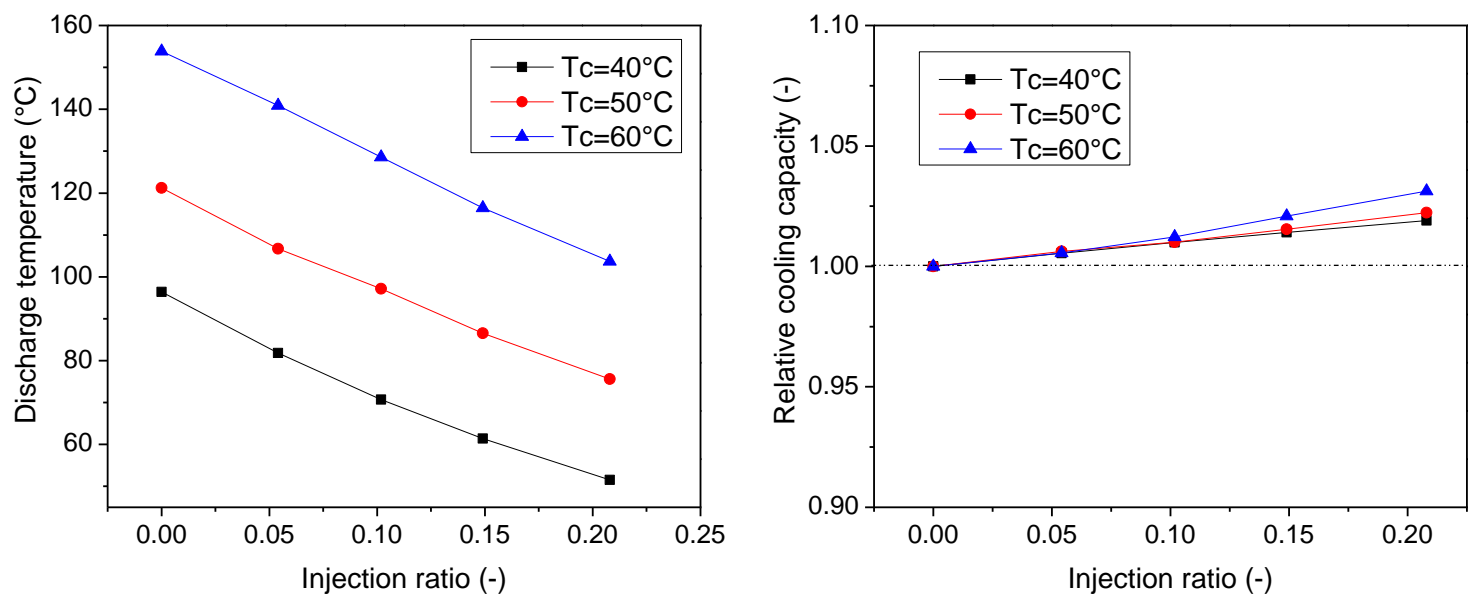

a) discharge temperature

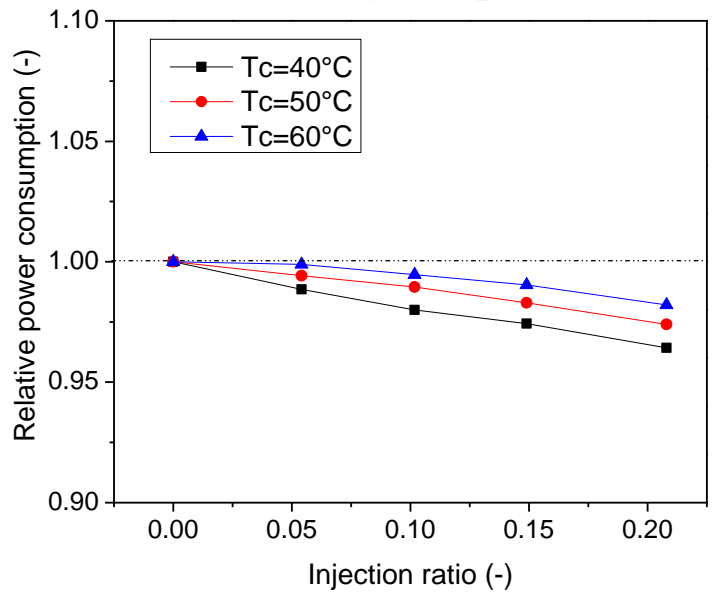

b) relative cooling capacity

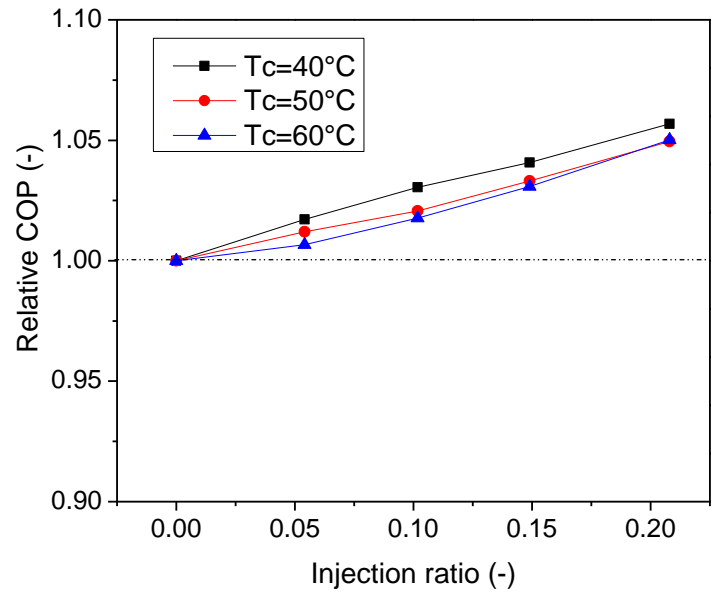

c) relative power consumption

d) relative $\mathrm{COP}$

Fig. 8. Effects of liquid injection ratio on the compressor performance $\left(T_{\mathrm{e}}=-5^{\circ} \mathrm{C}\right)$. 


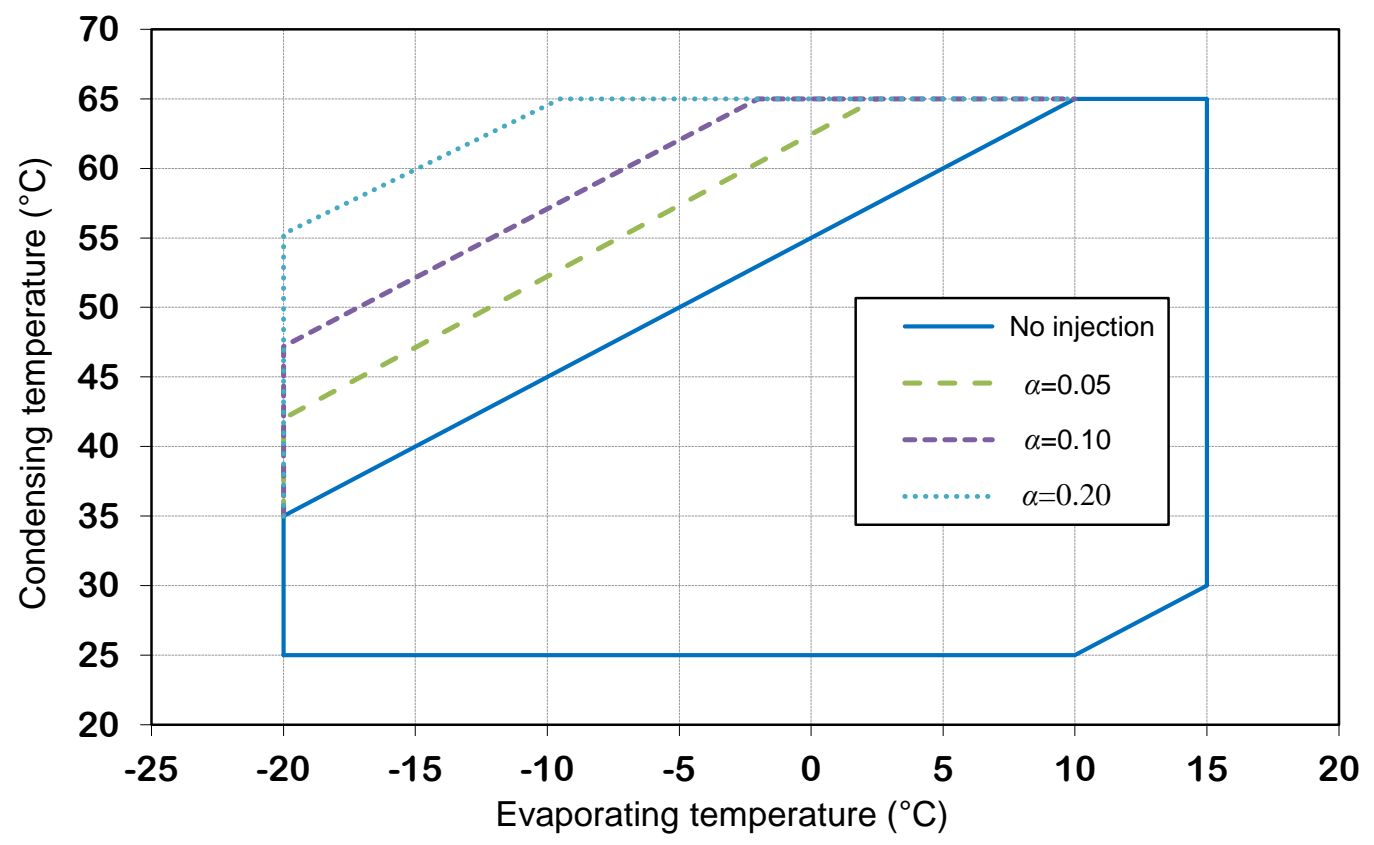

Fig. 9. Operating envelopes of R32 scroll compressor with different injection ratios. 


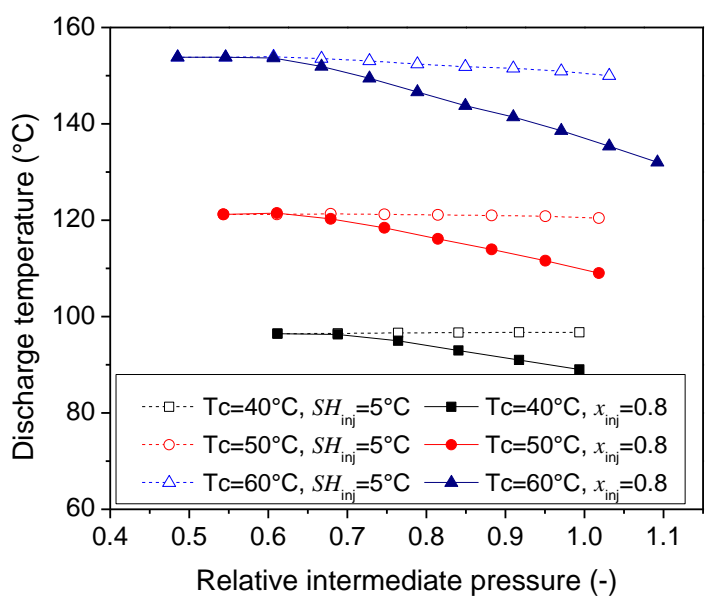

a) discharge temperature

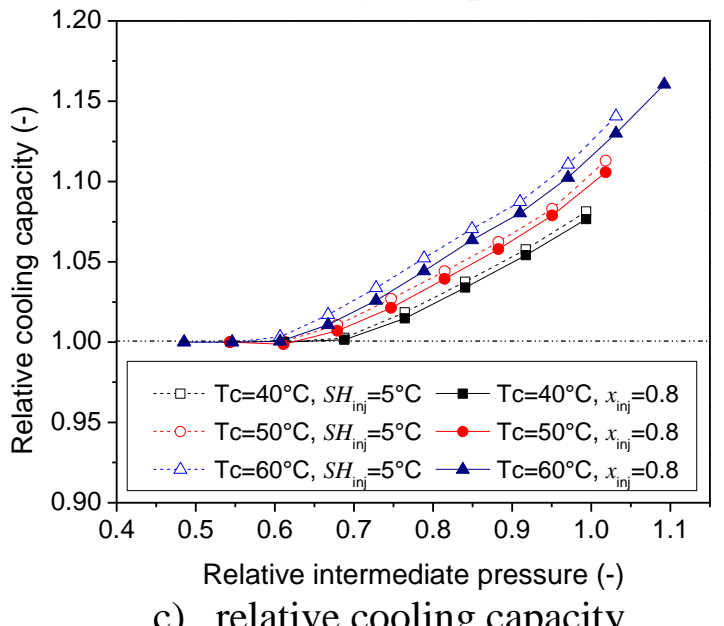

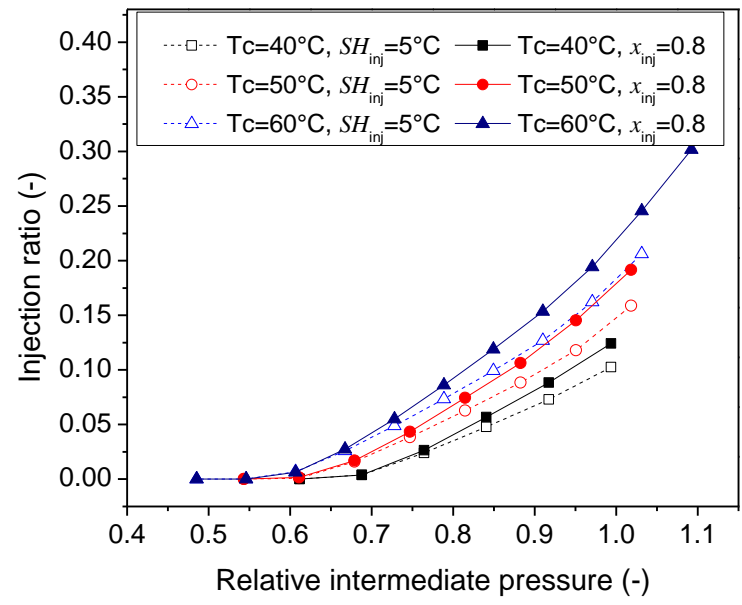

b) injection ratio

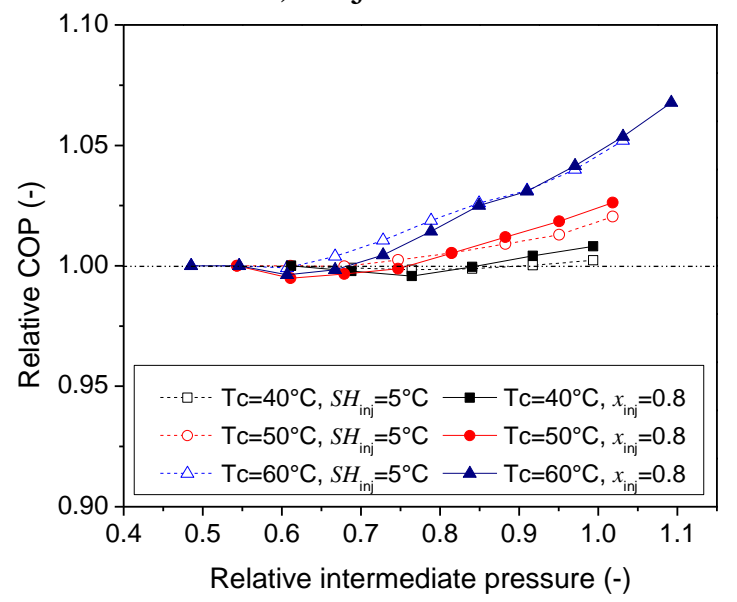

d) relative $\mathrm{COP}$

Fig. 10. Effects of injected refrigerant states on the compressor performance $\left(\mathrm{Te}=-5^{\circ} \mathrm{C}\right)$. 


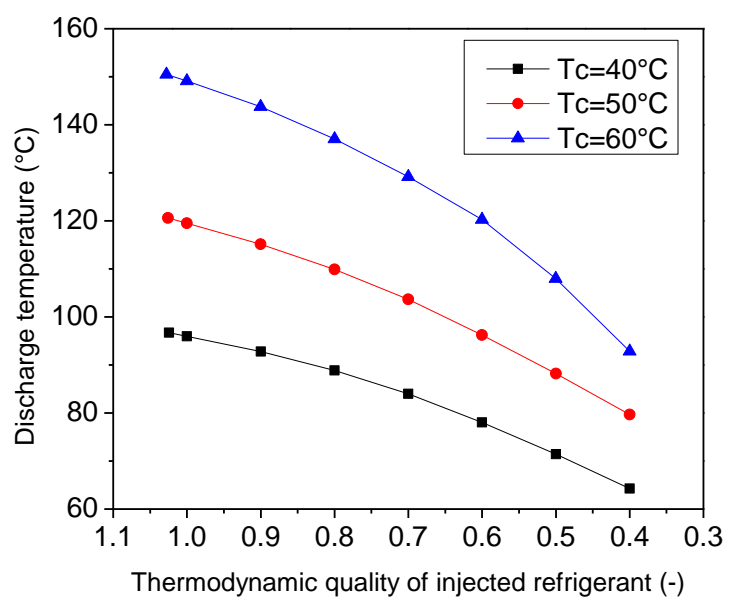

a) discharge temperature

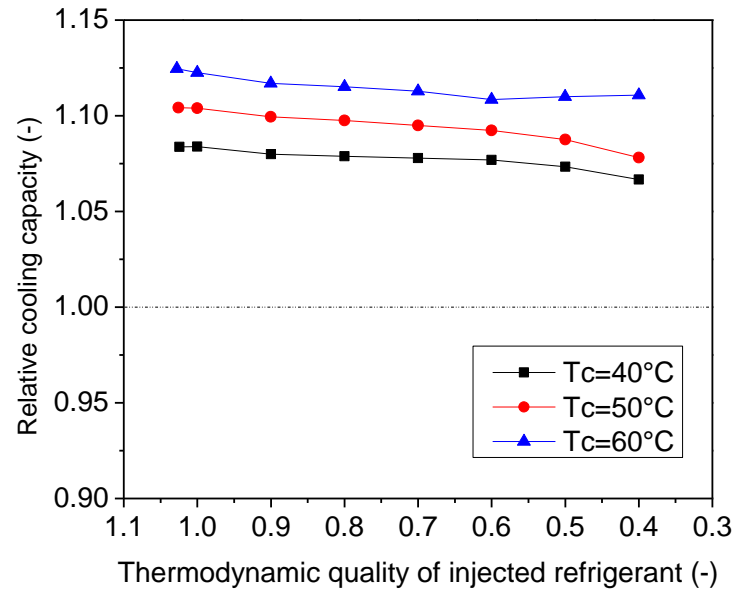

c) relative cooling capacity

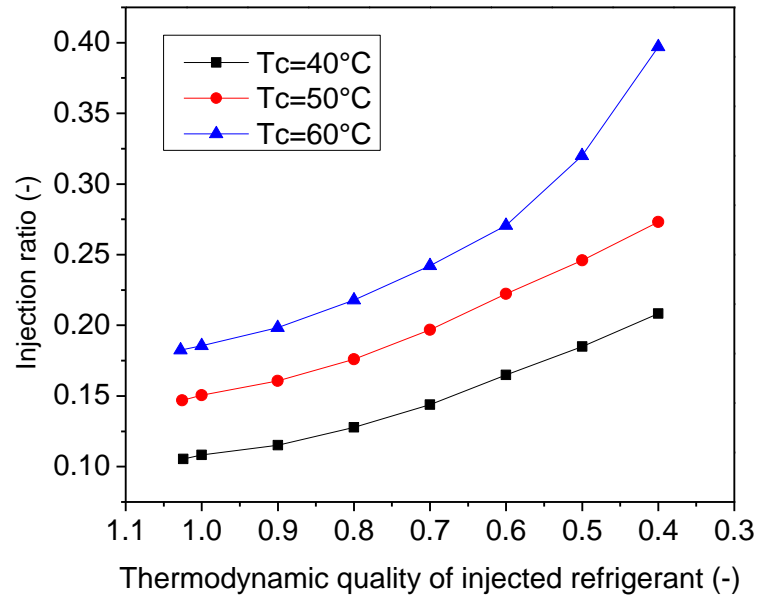

b) injection ratio

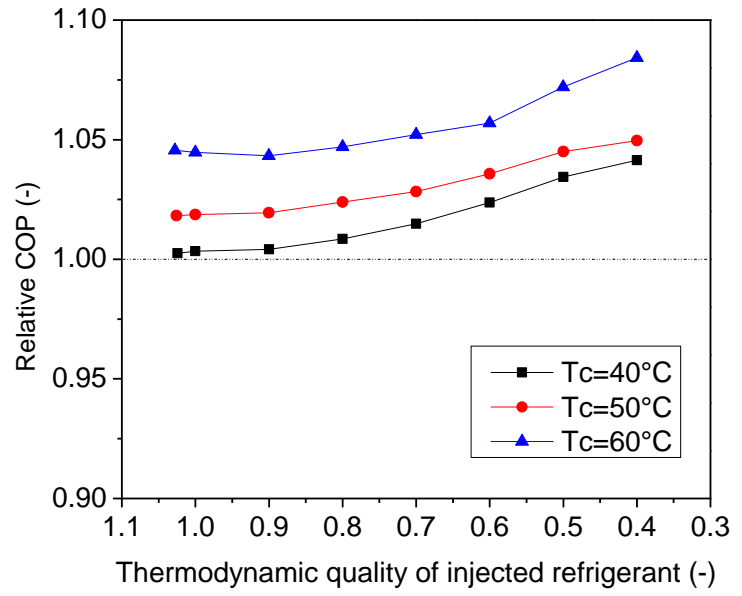

d) relative $\mathrm{COP}$

Fig. 11. Effects of injected thermodynamic quality on the compressor performance $\left(\beta=1.0\right.$ and $\left.\mathrm{Te}=-5^{\circ} \mathrm{C}\right)$. 


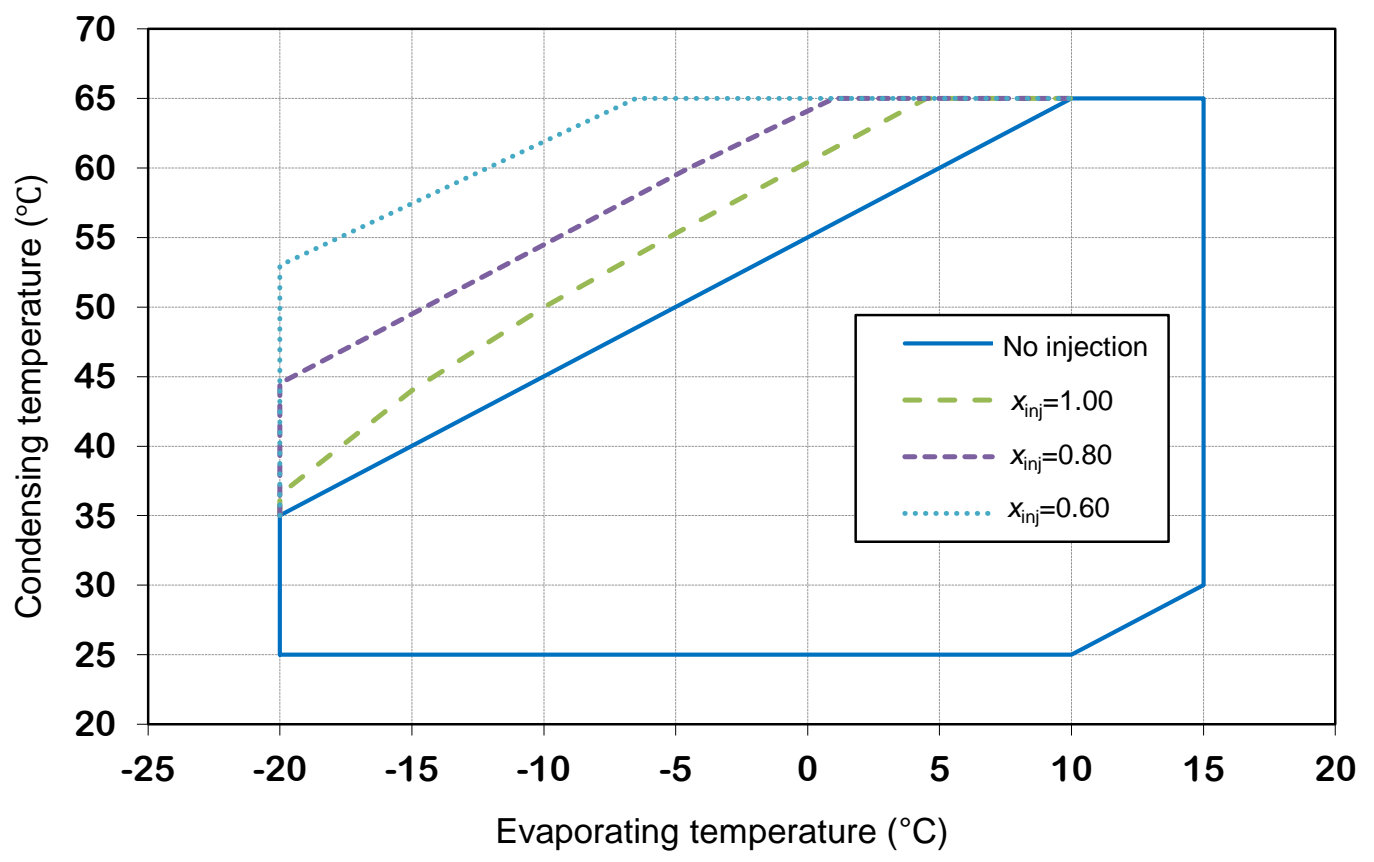

Fig. 12. Operating envelopes of R32 scroll compressor with various qualities of injected refrigerant $(\beta=1.0)$. 


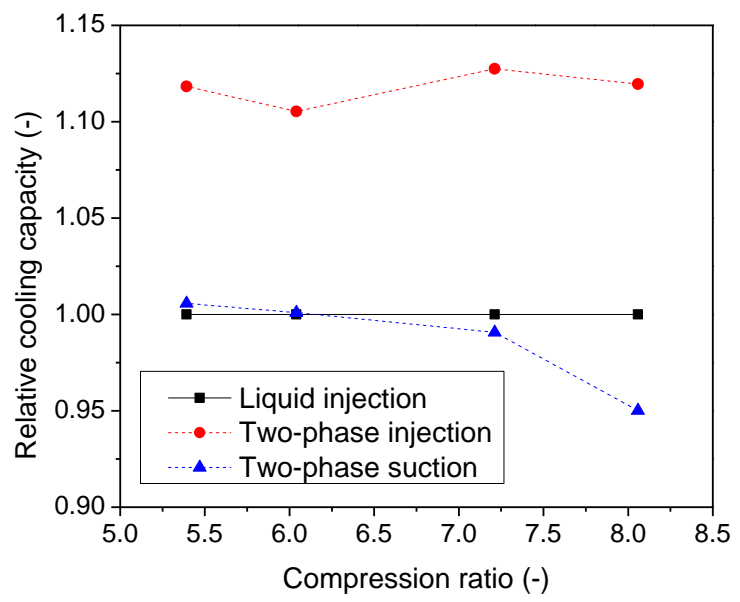

a) relative cooling capacity

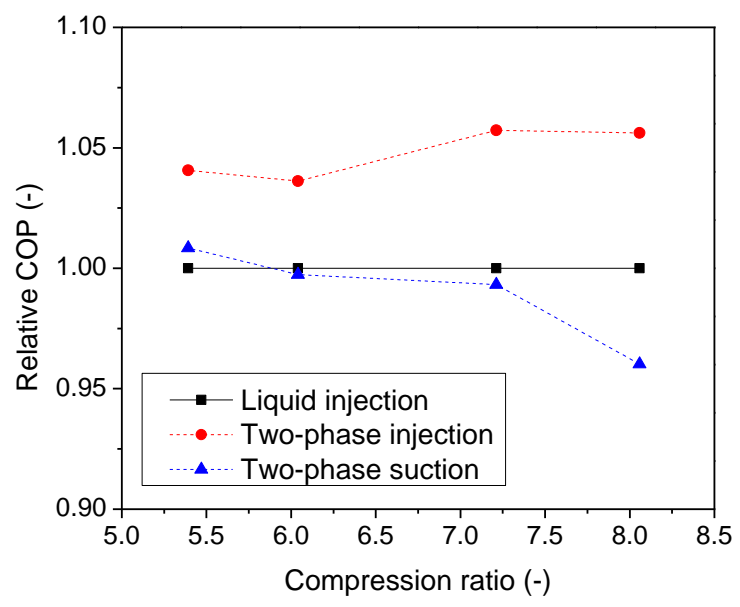

b) relative $\mathrm{COP}$

Fig. 13. Performance comparison of R32 scroll compressor with different discharge temperature-decreasing methods. 
Table 1

Parameters of the scroll compressor.

\begin{tabular}{ll}
\hline Item & Value \\
\hline Basic circle radius $(\mathrm{mm})$ & 3.36 \\
Orbiting radius $(\mathrm{mm})$ & 5.06 \\
Thickness of the scroll $(\mathrm{mm})$ & 5.49 \\
Height of the scroll $(\mathrm{mm})$ & 40.60 \\
Initial involute angle $(\mathrm{rad})$ & 0 \\
Inner wrap starting angle $(\mathrm{rad})$ & 1.33 \\
Outer wrap starting angle $(\mathrm{rad})$ & -0.28 \\
Number of the circles & 3.00 \\
Radical gap with $(\mu \mathrm{m})$ & 15 \\
Flank gap with $(\mu \mathrm{m})$ & 20 \\
Location of injection ports $^{\text {a }}(\mathrm{rad})$ & 0.02 \\
Radius of injection ports $(\mathrm{mm})$ & 3 \\
\hline
\end{tabular}

${ }^{a}$ location of injection ports is relative to the orbiting angle where suction pocket closes. 
Table 2

Four conditions selected for performance comparison of the three methods.

\begin{tabular}{cccc}
\hline Conditions & $T_{\mathrm{e}}\left({ }^{\circ} \mathrm{C}\right)$ & $T_{\mathrm{c}}\left({ }^{\circ} \mathrm{C}\right)$ & $\begin{array}{c}\text { Compression ratio } \\
\left(p_{\text {dis }} / p_{\text {suc }}\right)\end{array}$ \\
\hline 1 & & & 5.39 \\
2 & -10 & 50 & 6.04 \\
3 & -10 & 55 & 7.21 \\
4 & -15 & 55 & 8.06 \\
\hline
\end{tabular}

